\title{
THE EFFECTIVENESS OF TWO ER:YAG LASER SYSTEMS ON ROOT CANAL CLEANLINESS: A COMPARATIVE SCANNING OF ELECTRON MICROSCOPE STUDY
}

\author{
Ahmed Bamanie*
}

\begin{abstract}
Aim: To evaluate the cleaning ability of two different systems of Er:YAG laser endodontic probes and to compare them with conventional root canal treatment.

Materials and Methods: Forty five root canals from twenty eight extracted permanent human teeth were cleaned and shaped up to size 40 and 0.06 taper with crown down technique using Profile ${ }^{\circledR}$ rotary nickel titanium instrument under frequent irrigation with Dakins ${ }^{\circledR}$ solution. The root canals were randomly distributed in three groups of fifteen root canals each. Group C: Root canals finally flushed with EDTA $3 \%$ (Tubulicid plus $^{\circledR}$ ) for one minute. Group O: Root canals finally irradiated with Er:YAG laser using (Opus $20^{\circledR}$ ) with endodontic probe (RCLase ${ }^{\mathrm{TM}}$ ) for one minute. Group K: Root canals finally irradiated with Er:YAG laser using (KaVo KEY Laser ${ }^{\circledR}$ ) with optical fiber plug for one minute. The roots were split longitudinally and prepared for scanning electron microscope (SEM). Each root canal was evaluated for debris and smear layer at the coronal, middle and apical thirds.
\end{abstract}

Results: Significantly less smear layer $(\mathrm{P}<0.05)$ was found in the apical third of laser treated root canals compared with the control group, but no significant difference was found between the two laser probe systems. No significant difference $(P>0.05)$ regarding the amount of debris would be found between the three groups.

Conclusions: The use of laser seems to be more effective than conventional root canal treatment in removing smear layer in the apical third regardless the laser probe system.

.Keywords: Canal cleanliness, Debris, Laser, Scanning Electron Microscope, Smear layer

\section{INTRODUCTION}

Requirements for successful root canal therapy are thought to be a thoroughly cleaned, shaped and a three dimensionally tightly sealed canal (West and Roane 1998).
It is widely accepted that such a mission cannot be fulfilled by mean of mechanical instrumentation only, due to the fact that after mechanical preparation of dentin, a smear layer is produced every time a dentin surface is being cut (McComb and Smith 1975).

* King Fahad Medical City, Dental department, Hospital Dentistry. 
The smear layer contains inorganic and organic substances, which include fragments of odontoblastic processes, microorganisms, their byproducts, and necrotic materials (Pashley 1992).

The smear layer acts as a physical barrier, preventing the penetration of root canal sealers into the dentinal tubules (Øksan et el. 1993).

In addition, smear layer may give a negative influence on the sealing ability of obturated canals, since it is a porous and weakly adherent interface between the obturation material and the dentine wall (White et al. 1984, Kennedy et al. 1986), and affecting the efficacy of obturation (Sen et al.1995, Behrend et al. 1996).

Removal of smear layer promotes penetration of the endodontic sealer into the exposed dentinal tubules, which increase the contact surface between the sealer and dentine and allows a mechanical bond between them (Pecora et al. 2001), moreover its removal is necessary since smear layer has been reported not only to harbour microorganisms, but also to seals the dentinal tubules and their enclosed microorganisms. Therefore, the presence of smear layer may prevent any intracanal medication from disinfecting such tubules (Sjögren and Sundqvist 1987).

In addition, following mechanical preparation, remnants loosely attached to the canal wall have been observed i.e. dentin chips, pulp tissue parts, and other particles which were classified as debris (Hülsmann et al. 1997).

Consequently, since mechanical preparation of root canals alone seems not to fulfill the requirement for successful root canal treatment, because debris and smear layer will not be eliminated, the use of irrigating solutions and other chemical agents have been advocated in combination with mechanical instrumentation.

Sodium hypochlorite $(\mathrm{NaOCl})$ is a widely used irrigant in endodontic treatment because of its solvent action on organic pulp tissue and its bacteriocidal and cleansing properties, It dose not, however, completely remove the smear layer produced during instrumentation of the root canal (Wayman et al. 1979).

In order to remove the inorganic part of the smear layer it is suggested to use the $\mathrm{NaOCl}$ irrigation in combination with chelating agent (Yamada et al. 1983).

Ethylenediamine tetra-acetic acid (EDTA) has the ability to remove the inorganic elements of the smear layer (Aktener and Bilkay 1993). Therefore, sequential use of $\mathrm{NaOCl}$ and EDTA solutions was recommended (Yamada et al. 1983, Garberoglio and Becce 1994).

It has been claimed by the manufacturer that the additives in tubulicid plus (EDTA 3\%) decrease the viscosity and the surface tension. Therefore, its high wetting ability and improved infiltration may allow the removal of the smear layer (Liolios et al. 1997).

However, studies have shown that chemomechanical instrumentation with different instruments, methods and techniques was unable to totally remove the smear layer and debris from the root canal walls (Mayer et al. 2002, Hülsmann et al. 2001, Siqueira et al. 1997).

Recently, the effect of laser treatment with Er:YAG, CO2, Nd:YAG, Argon and other types of irradiation has been investigated on the root canal walls by several researchers (Takahashi et al. 1996, Matsuoka et al. 1998, Takada et al. 1998a,b,c 1999, Stabholz et al. 2003).

The word LASER is an acronym for Light Amplification by Stimulated Emission of Radiation. It is produced by a device that transforms light of various frequencies into a chromatic radiation in the visible, infrared and ultraviolet regions with all the waves in phase capable of mobilizing immense heat and power when focused at close range. 
Since the ruby laser was developed by Maiman (1960), Researchers have investigated laser applications in dentistry and clinicians began using other lasers, such as argon (Ar), carbon dioxide $\left(\mathrm{CO}_{2}\right)$, neodymium: yttrium-aluminum-garnet (Nd:YAG), and erbium: yttrium-aluminum-garnet (Er):YAG lasers.

The first laser used in endodontics was reported by Weichman \& Johnson (1971) who attempted to seal the apical foramen in vitro by means of high power infrared $\left(\mathrm{CO}_{2}\right)$ laser.

Although their goal was not achieved, sufficient relevant and interesting data were obtained to encourage further studies in order to obtain more information regarding this laser's interaction with dentin.

Since then, many papers on laser applications in dentistry have been published (Midda and RentonHarper 1991, Pick 1993, Wigdor et al. 1993, 1995), with growing interest in this topic in the last decade.

Er:YAG laser irradiation was reported to be more effective in removing the smear layer and debris from the root canal walls than other types of laser (Takahashi et al. 1996, Matsuoka et al. 1998, Takada et al. 1998a, b, c 1999).

Er:YAG laser with wavelength of $2940 \mathrm{~nm}$ has an active medium of solid crystal of Yttrium Aluminum Granet that is doped with Erbium. This wavelength is near the boundary of the near and mid infrared, invisible, and non-ionizing portion of the spectrum (Fig. 1). Additionally, it has the highest absorption in water of any dental wavelength and also has a very high affinity for hydroxyapatite.

The laser energy couples into the hydroxy radical in the apatite crystal, and the water that bounds to the crystalline structures of the tooth will readily and easily absorb the laser light. The vaporization of the water within the mineral substrate causes a massive volume expansion, and this expansion causes the surrounding mineral to literally explode

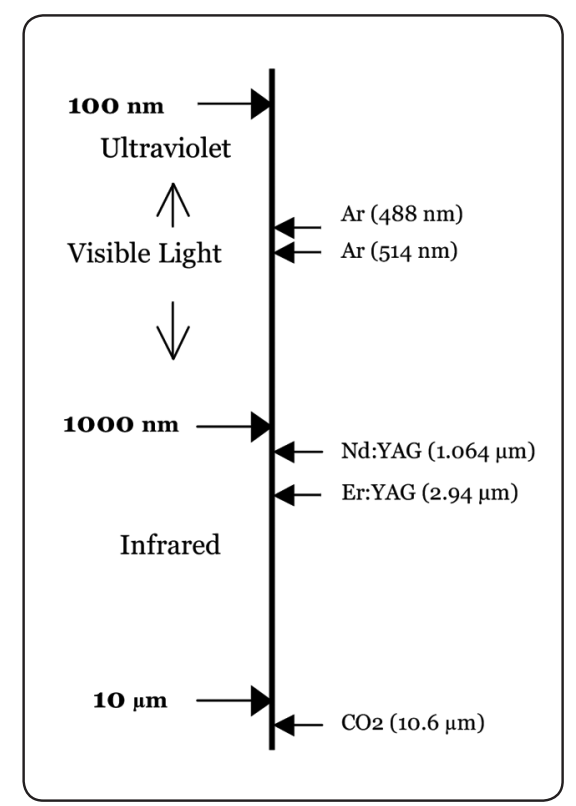

Fig. (1) Identification of different types of dental lasers.

away. The free running pulse mode of Er:YAG laser provides the peak power to facilitate such explosive expansion.

Er:YAG laser, when applied on dentin , promotes its ablation (Keller and Hibst 1989), vaporizing the smear layer and exposing dentinal tubules (Takeda et al. 1999). It also modifies the dentinal surface morphologically, creating a micromechanical retention pattern (Tanji et al. 1997).

Previously the application of Er:YAG laser was limited to rigid delivery systems in non-contact mode. The development of superior light conductive material distinctly broadened the spectrum of this laser's capabilities. Even teeth with narrow or bent root canals can easily be treated.

The emitted energy of Er:YAG laser system used in Endodontics, can be delivered into the root canal system either by a thin optical fiber or a flexible hollow tube.

The optical fiber plugs come in different sizes (fig. 2) (one ring correspond to size $30 / 28 \mathrm{~mm}$, two rings correspond to size $40 / 28 \mathrm{~mm}$ and three rings correspond to size $50 / 28 \mathrm{~mm}$ ) at the tip of the fiber. 
When using the optical fiber The emission of the Er:YAG laser is carried out through a single opening at its tip directed along the long axis of the fiber. Therefore, the laser tip must slide gently in a circular motion from the apical portion to the coronal portion, while pressing the laser tip against the root canal walls in the presence of irrigant (Schoop et al. 2002, Matsumoto 2000).

On the other hand, the hollow tube tip allows lateral emission of the irradiation (side - firing) (fig. 3) (Stabholz et al. 2003).

This new side firing spiral tip (RCLase ${ }^{\mathrm{TM}}$ ) was designed to fit the shape and the volume of root canals prepared by $\mathrm{Ni}-\mathrm{Ti}$ rotary instrumentation. It emits the Er:YAG laser irradiation laterally to the walls of the root canal through a spiral slit located all along the tip, while the tip is sealed at its far end (Fig. 4). Therefore, it has to be inserted to the working length then moved with lasing in an up and down movement within a range of 1-2 $\mathrm{mm}$ in the presence of irrigant, as the manufacturer recommended.

The purpose of this study was to evaluate the cleaning ability of the two different systems of Er:YAG laser endodontic probes and to compare it with conventional root canal treatment.

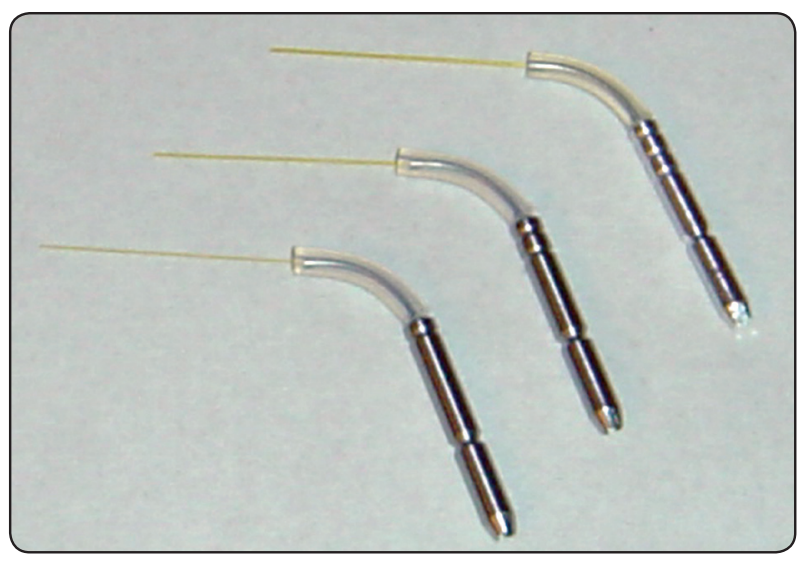

Fig. (2) Optical fiber plugs.

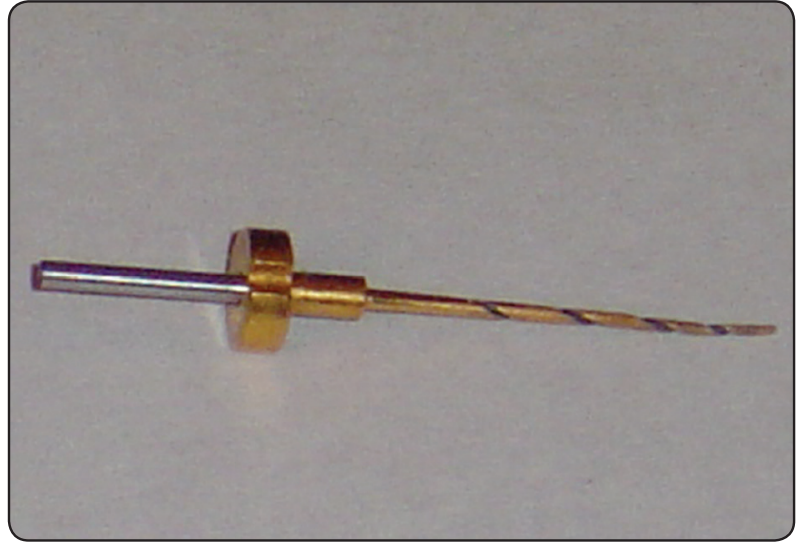

Fig. (3) Hollow tube, RCLase ${ }^{\mathrm{TM}}$ side firing spiral tip.

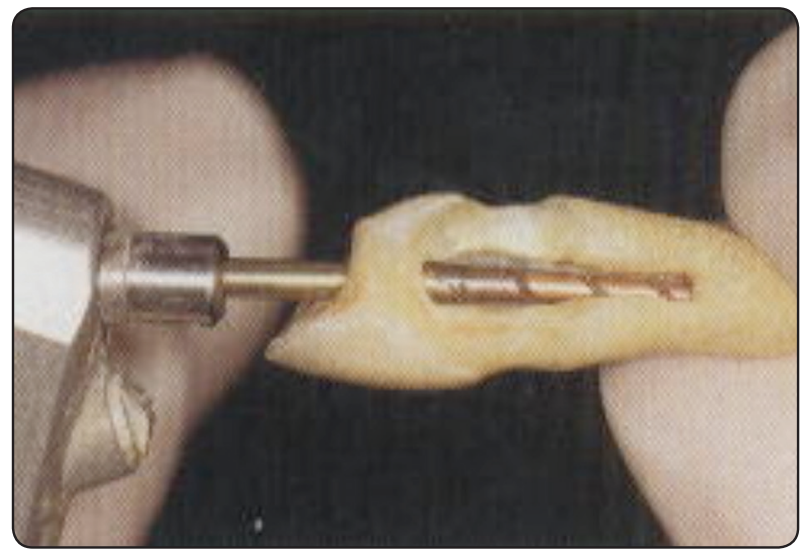

Fig. (4) The RCLase ${ }^{\mathrm{TM}}$ tip in the root canal of an extracted tooth.

\section{MATERIALS AND METHODS}

Forty five root canals from twenty eight extracted human mature permanent teeth were used in this study.

Access cavities were prepared according to normal standards. The working length of each root canal was established $1 \mathrm{~mm}$ short of the apical foramen with a size $15 \mathrm{~K}$-type file. The root canals were cleaned and shaped up to ISO size 40 and 0.06 taper using crown-down preparation technique and Profile ${ }^{\circledR}$ (Dentsply Maillefer, Ballaigues, Switzerland) rotary nickel titanium instrument under irrigation with $2 \mathrm{ml} 0.5 \%$ sodium hypochlorite (Dakins ${ }^{\circledR}$, Apoteksbolaget, Sweden) 
solution between each file. The irrigant solution was delivered with a 30-gauge needle introduced into the canal as apically as possible without binding. Finally, the root canals were dried with absorbent paper points and distributed randomly into three groups of fifteen root canals each.

The first group served as the control (C). In this group the root canals were fully irrigated with EDTA 3\% (Tubulicid plus ${ }^{\circledR}$, Dental therapeutic AB, Sweden) for one minute followed by irrigation with $2 \mathrm{ml}$ of $0.5 \%$ sodium hypochlorite $\left(\right.$ Dakins $^{\circledR}$ ) as a final flush.

The second group $(\mathrm{O})$ root canals were fully irrigated with EDTA 3\% and irradiated with Er:YAG laser (Opus 20, Lumenis - Opus Dent, Israel). The side firing endodontic probe (RCLase ${ }^{\mathrm{TM}}$ ) was inserted to the working length. The root canals were irradiated at wavelength of $2.94 \mu \mathrm{m}$, energy of 100 $\mathrm{mJ}$ and pulsed mode at frequency of $10 \mathrm{~Hz}$, while moving the probe up and down in a range of $1-2 \mathrm{~mm}$ for 15 seconds. In addition they were reirrigated with EDTA and the laser probe was introduced and turned $90^{\circ}$ clockwise to irradiate for another 15 sec. This was repeated four times to achieve $360^{\circ}$ radiation of the root canals for $1 \mathrm{~min}$.

The third group $(\mathrm{K})$ of root canals were fully irrigated with EDTA 3\% and irradiated with Er:YAG laser (KaVo KEY Laser ${ }^{\circledR} 3$-1243- Germany). The optical fiber plug (40/28) was inserted to the working length. The root canals were irradiated at wavelength of $2.94 \mu \mathrm{m}$, energy of $100 \mathrm{~mJ}$ and pulsed mode at frequency of $10 \mathrm{~Hz}$, while moving the probe in a circling movement from the apex to the crown in $15 \mathrm{sec}$. This was repeated four times to achieve a total of 1 min radiation of the root canals.

The teeth were then stored in Chlorhexidine (0.5\% Chlorhexidine, Apotekbolaget, Sweden).

The roots were split in halves using a diamond disc (Horico ${ }^{\circledR}$ Hopf, Ringleb and CO. GMBH and CIE - Germany) preparing two parallel longitudinal grooves on both sides. A plastic instrument was used to complete the separation. The root halves were cleaned and dried using water and air blast. Each root half was examined under light microscope to determine the status for further SEM examination. The most suitable root halves were left to dry over night in an oven at $37.5^{\circ} \mathrm{C}$ and mounted on aluminum stubs.

The roots were coated with platinum using a sputtering machine (SCD 500, Bal-Tec AG, Balzers, and Lichtenstein).

A SEM (JSM-JOEL CO., Ltd., Tokyo, Japan) was used in the examination of roots, using magnification of x400; Digital microphotographs were taken of each root canal at the coronal, middle and apical thirds.

Two operators performed blind evaluation of the digital microphotographs for the scoring of debris and smear layer.

Debris was defined as dentine chips, pulp remnants and particles loosely attached to the canal wall (Hülsmann et al. 1997) and scored as follow:

Score 1: clean root canal wall, very slight debris.

Score 2: slight debris (Fig. 5).

Score 3: moderate amount of debris, less than $50 \%$ of the sample surface covered (Fig. 6).

Score 4: substantial debris, more than $50 \%$ of the sample surface covered.

Score 5: the root canal surface was completely or almost completely covered.

Smear layer was defined as a film of debris attached to dentine and other surfaces consisting of dentine particles, remnants of vital or necrotic pulp tissue and bacterial products (McComb and Smith 1975) and scored as follow:

Score 1: No smear layer, open dentinal tubuli.

Score 2: Slight smear layer, most dentinal tubuli open. 
Score 3: Moderate smear layer, more than 50\% of dentinal tubuli open. (Fig. 7)

Score 4: More than moderate smear layer, less than $50 \%$ of dentinal tubuli open (visible).

Score 5: Homogenous smear layer covering the major parts of the surface, a few dentinal tubuli open (visible).

Score 6: Homogenous smear layer covering the surface, No dentinal tubuli open (visible, Fig. 8)

Score 7: Thick non-homogeneous smear layer covering the surface.

The Inter-Examiner reliability was estimated from 30 randomly selected Digital microphotographs using Cohen's kappa statistic $(x)$ according to the formula

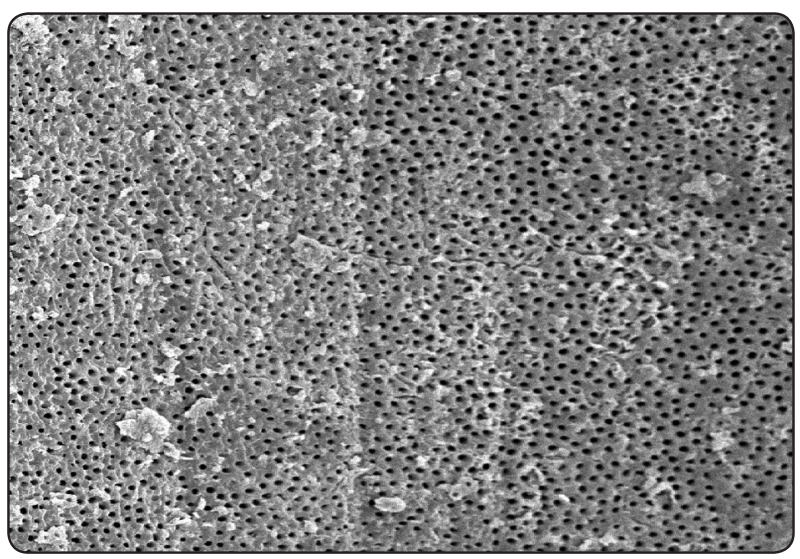

Fig. (5) Slight debris.

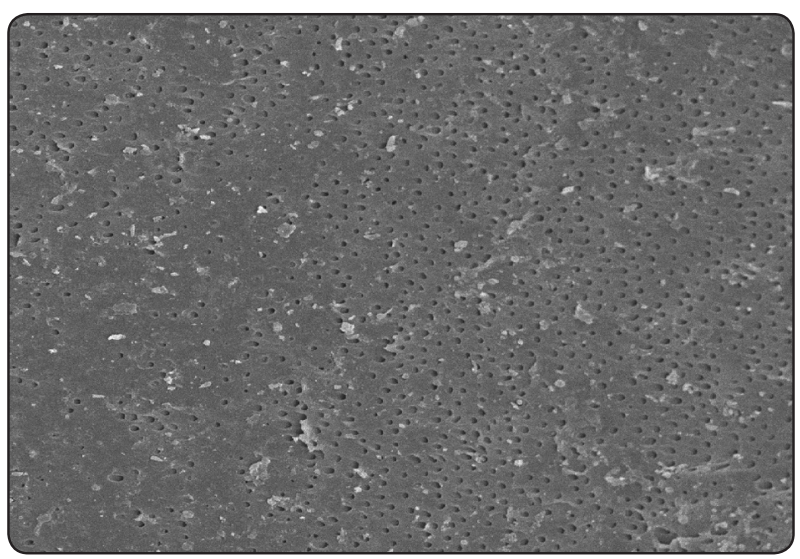

Fig. (7) Moderate smear layer.

$$
\begin{gathered}
\text { Ao }- \text { Ac } \\
x=---, \\
1-\text { Ac }
\end{gathered}
$$

Where Ao is the proportion of agreements in the scores that was actually observed by the examiners and Ac the proportion of agreements that could be expected by chance (Cohen 1960). The InterExaminer reliability found was $x=0.89$ indicating "perfect" agreement (Landis and Koch 1977). It is concluded that the error related to Inter-Examiner variability of assessments did not substantially influence the outcome.

Because of the ordinal nature of data, statistical analysis performed using Mann-Whitney rank test at a significant level of $\mathrm{P}<0.05$ for comparison between levels.

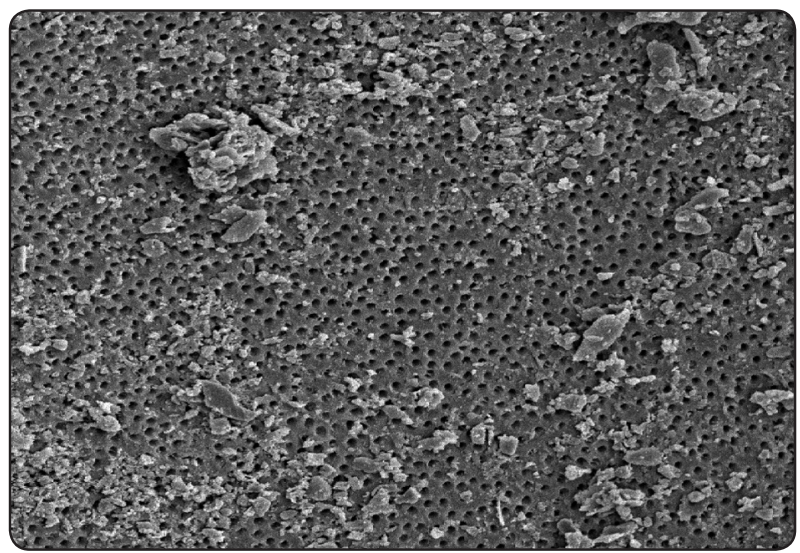

Fig. (6) Moderate amount of debris.

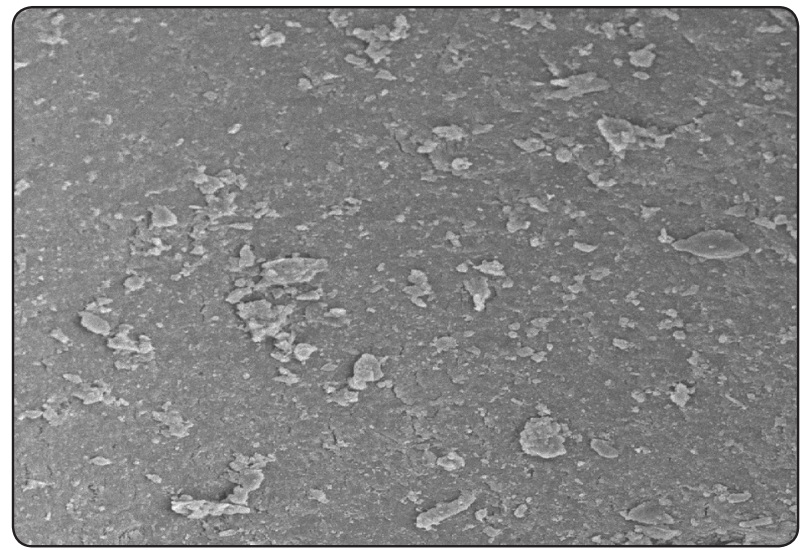

Fig. (8) Homogenous smear layer covering the surface. 


\section{RESULTS}

\section{Debris scores analysis}

All the three groups showed no significant difference $(\mathrm{P}>0.05)$ when compared to each other.

Most of the specimens showed scores in the coronal third, clean to slight debris (Fig. 9), in the middle third, slight to moderate debris (Fig. 10) and in the apical third slight to moderate debris except in group (O) which showed slight debris in most of the specimens in apical third, But no significant difference found with the other two groups (Fig. 11).

\section{Smear layer scores analysis}

In the most of specimens the coronal third showed slight to more than moderate smear layer with an exception in group (C) which showed more number of specimens with homogenous smear

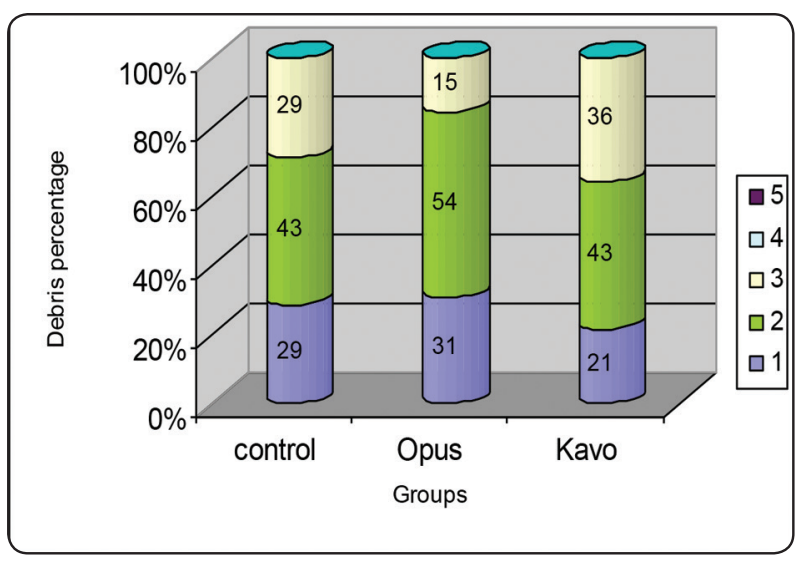

Fig. (9) Coronal Debris (\%).

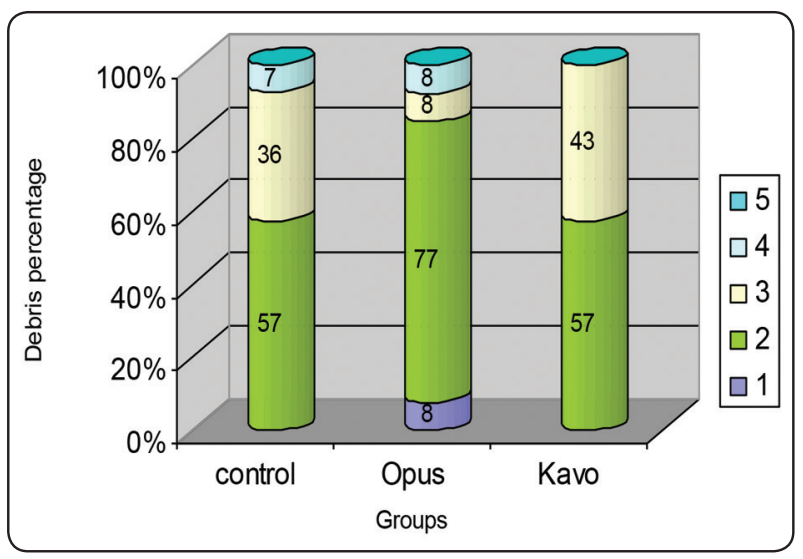

Fig. (11) Apical Debris (\%). covering the major parts of the surface (Fig. 12), But no significant difference $(\mathrm{P}>0.05)$ was found between the three groups.

The middle third showed most specimens with moderate to homogenous smear layer covering the major parts of the surface (Fig. 13). No significant difference $(\mathrm{P}>0.05)$ was found between the three groups.

The apical third, group (C) showed most specimens with a range of homogenous to thick non homogenous smear layer covering all surfaces, while groups $(\mathrm{O})$ and $(\mathrm{K})$ showed most specimens with a range of homogenous smear layer covering major parts to all of the surfaces but more number of specimens in group $(\mathrm{K})$ showed more than moderate smear layer (Fig. 14). The only significant difference was found when group (C) was compared with group $(\mathrm{O})(\mathrm{P}<0.014)$ and group $(\mathrm{K})(\mathrm{P}<0.01)$ while no significant difference was found when group $(\mathrm{O})$ was compared with group $(\mathrm{K})$.

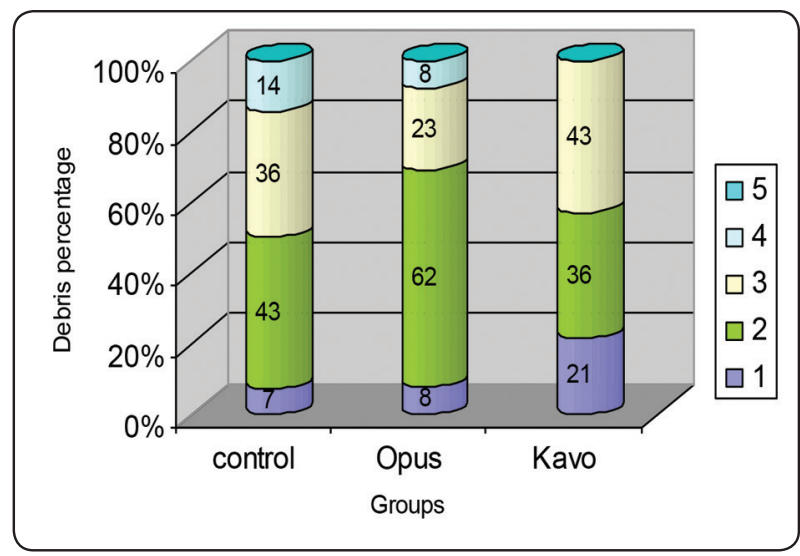

Fig. (10) Middle debris (\%).

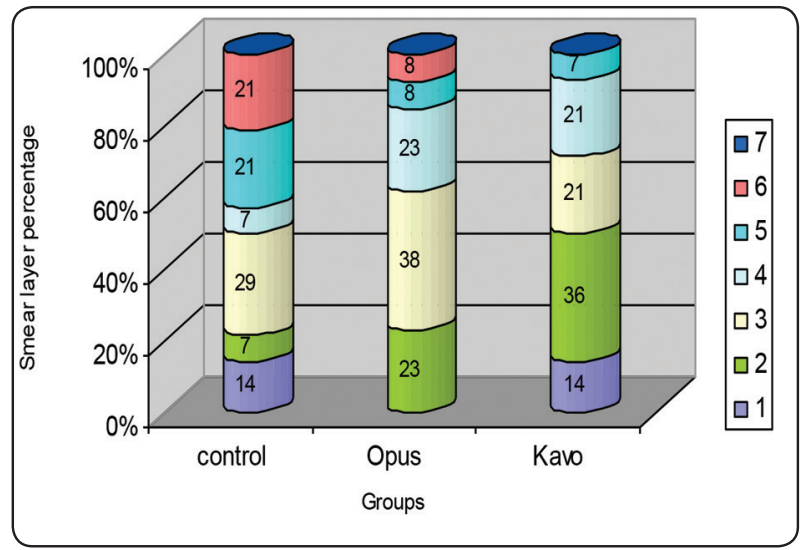

Fig. (12) Coronal Smear layer (\%). 


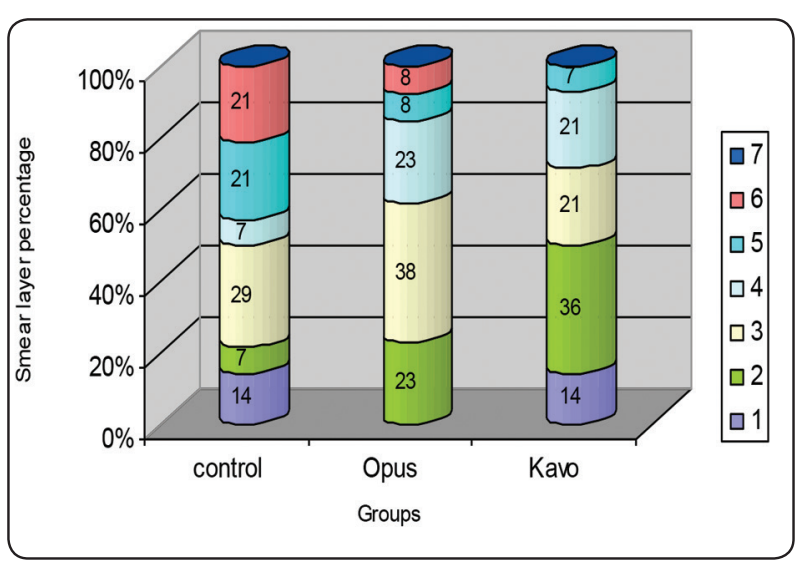

Fig. (13) Middle Smear layer (\%).

\section{DISCUSSION}

Successful endodontic treatment relies to a great extent on complete cleaning of the root canal system. Infected dentin and pulpal tissue can endanger therapy outcome. Conventional root canal treatment aims at the removal of the infected pulp, dentin and smear layers by using mechanical techniques and dissolving irrigants. Several studies indicate that these techniques are only partly successful (Mayer et al. 2002, Hülsmann et al. 2001, Siqueira et al. 1997). On the other hand, using lasers have been investigated and achieved better results (Arrastia et al.1998, Matsuoka et al. 1998, Takeda et al. 1998c, 1999).

In the present study, the canals were prepared to a size 40 taper 0.06 since it was observed that the canals should be enlarged at least to this size in order to provide access for the large RCLase ${ }^{\mathrm{TM}}$ tip.

In addition, canals preparation were done by using rotary instrumentation system which is more intensive than manual instrumentation in dentinal shaving and produce a thicker smear layer and more debris (Liolios et al. 1997).

The result of the present study confirmed previous reports that a final flush with EDTA, which was intended for the removal of the smear layer, did not produce the expected smear free surfaces especially

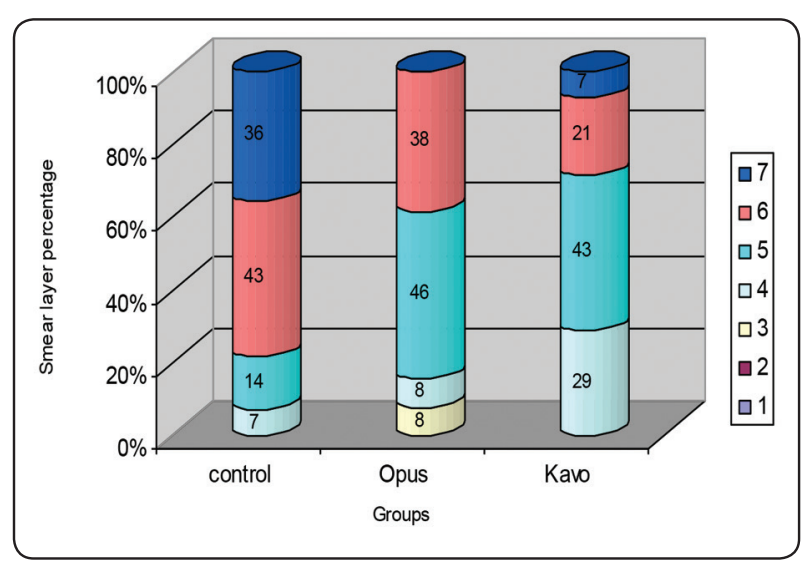

Fig. (14) Apical Smear layer (\%).

in the apical one third of the canals (Ciucchi et al. 1989).

It may be argued that the present outcome of unclean canals may be due to the low concentration of irrigating solution. However, the choice of low concentrations of EDTA and sodium hypochlorite that were used was supported in earlier studies when no difference in smear layer removal effect between low concentration 3\% EDTA and high concentration 17\% EDTA was reported (Garberoglio and Becce 1994). Furthermore, studies carried out on evaluation of tissue dissolving ability of the available concentrations of sodium hypochlorite found no difference between high and low concentration (Baumgartner and Cuenin 1992).

The use of laser has certainly shown great promise in root canal therapy especially when used to remove the smear layer remaining on the instrumented root canal walls of the middle and apical one third (Takeda et al. 1999).

In this study, it was confirmed that Er:YAG laser had the capability to remove smear layer and debris more efficiently from root canals in the apical one third since it showed a statistical significant difference when each delivery system of Er:YAG laser was compared with conventional root canal treatment in cleaning ability of root canal walls. 
Moreover, a laser effect on periodontal tissues must be considered. Therefore, it is very important to select the appropriate parameters and methods.

The emission of the irradiation must be pulsed, with a short thermal relaxation time and short pulse duration time so that harmful increase in the temperature are minimized and energy to be added to the surface in a short enough period of time to cause expansion and vaporization.

The parameters used in this study were irradiation of Er:YAG with pulse energy of $100 \mathrm{~mJ}$ and pulse rate of $10 \mathrm{~Hz}$ since it has been shown to be the most effective laser in cleaning prepared root canals in comparison with other laser wavelengths (Takeda et al. 1999).

The emission of Er:YAG laser energy from the tip of the optical fiber was directed along the root canal and seems to make a sharp angle with the lateral root canal walls since these root canals were prepared in a tapering shape, While the hollow tube (RCLase ${ }^{\mathrm{TM}}$ ) emits the Er:YAG laser laterally perpendicular to the lateral root canal walls.

On the other hand, direct emission of the laser irradiation from the tip of the optical fiber in the vicinity of the apical foramen of the tooth may result in transmission of the irradiation beyond the foramen, while the hollow tube (RCLase ${ }^{\mathrm{TM}}$ ) is sealed at its far end for more secure irradiation inside the root canals but not incase of presence of short lateral canals.

However, when both delivery systems of Er:YAG laser were compared with each other no statistically significant difference in cleaning ability of root canal walls was found.

In several previous studies four or five index scoring system were used to evaluate the smear layer with a wide range in between every two scores which is not giving good chance to sharply evaluate every specimen (Hülsmann et al. 1997, 1999, Hülsmann et al. 2001, Takeda et al. 1998b, 1999, Rome et al. 1985).
In the present study, the smear layer was evaluated using a seven index scoring system which limits the range in between the scores and giving the chance to have a sharper evaluation for every specimen when compared with four or five index scoring system. On the other hand this new scoring system was confusing in some of the specimen's evaluation due to its close range. However, Inter-Examiner Reliability test showed a perfect agreement (Landis and Koch 1977).

Debris was evaluated using a five index scoring system. During smear layer evaluation we noticed that, it was not easy to evaluate the smear layer accurately in some specimens that are partially or completely covered by debris.

Finally, no carbonization, cracks, fusion of dentin or crystallization of smear layer were found in any of the specimen.

\section{CONCLUSIONS}

The use of laser seems to be more effective than conventional root canal treatment in removing smear layer in the apical third regardless the laser probe system.

\section{REFERENCES}

1. Aktener BO, Bilkay U ( 1993) Smear layer removal with different concentrations of EDTA-ethylenediamine mixtures. Journal of Endodontics 19, 228-31.

2. Arrastia-Jitosho AM, Liaw LH, Lee W, Wilder-Smith P (1998) Effect of a $532 \mathrm{~nm}$ Q-switched nanosecond pulsed laser on dentin. Journal of Endodontics 24, 427-431.

3. Baumgartner JC, Cuenin PR (1992) Efficacy of several concentrations of sodium hypochlorite for root canal irrigation. Journal of Endodontics 18, 605-12.

4. Behrend GD, Gutler CW, Gutmann JL (1996) An in vitro study of smear layer removal and microbial leakage along root canal filling. International Endodontic Journal 29, 99-107.

5. Ciucchi B, Khettabi M, Holz J (1989) The effectiveness of different endodontic irrigation procedures on the removal 
of the smear layer: a scanning electron microscopic study. International Endodontic Journal 22, 21-8.

6. Cohen J (1960) A coefficient of agreement for nominal scales. Educational Psychological Measurement 20,37-46.

7. Garberoglio R, Becce C (1994) Smear layer removal by root canal irrigants. A comparative scanning electron microscopic study. Oral Surgery, Oral Medicine and Oral Pathology 78, 359-67.

8. Glossen CR, Haller RH, Dove SB, del Rio CE (1995) A comparison of root canal preparations using $\mathrm{Ni}-\mathrm{Ti}$ hand, $\mathrm{Ni}-\mathrm{Ti}$ engine-driven, and K-Flex endodontic instruments. Journal of Endodontics 21, 146-51.

9. Hülsmann M, Gambal A, Bahr R (1999) An evaluation of root canal preparation with the automated Excalibur endodontic handpiece. Clinical Oral Investigations 3, 70-8.

10. Hülsmann M, Rummelin C, Schafers F (1997) Root canal cleanliness after preparation with different endodontic handpieces and hand instruments: a comparative SEM investigation. Journal of Endodontics 23, 301-6.

11. Hülsmann M, Schade M, Schafers F (2001) A comparative study of root canal preparation with HERO 642 and Quantec SC rotary Ni-Ti instruments. International Endodontic Journal 34, 538-46.

12. Keller U, Hibst R (1989) Experimental studies of the application of the Er:YAG laser on the dental hard substances. Part II. Light microscopic and SEM investigations. Laser in Surgery and Medicine 9, 345-51.

13. Kennedy W, Walker WA, Gough RW (1986) Smear layer removal effects on apical leakage. Journal of Endodontics 12, 21-7.

14. Matsumoto K (2000) Lasers in Endodontics. Dental Clinics of North America 44, 889-906.

15. Landis JR , Koch GG (1977) The measurement of observer agreement for categorical data. Biometrics 33, 159-174.

16. Liolios E, Economides $\mathrm{N}$, Parissis-Messimeris $\mathrm{S}$, Boutsioukis A (1997) The effectiveness of three irrigating solutions on root canal cleaning after hand and mechanical preparation. International Endodontic Journal 30, 51-57.

17. Maiman TH (1960) Stimulated optical radiation in ruby. Nature 187, 493-4.

18. Matsuoka E, Kimura Y, Matsumoto K (1998) Studies in removal of debris near the apical seats by Er:YAG laser and assessment with a fiberscope. Journal of Clinical Laser
Medicine and Surgery 16, 255-61.

19. Mayer B, Peters OA, Barbakow F (2002) Effects of rotary instruments and ultrasonic irrigation on debris and smear layer scores: a scanning electron microscopic study. International Endodontic Journal 35, 582-9.

20. McComb D, Smith DC (1975) A preliminary scanning electron microscopic study of root canals after endodontic procedures. Journal of Endodontics 1, 238-42.

21. Midda M, Renton-Harper P (1991) Lasers in dentistry. British Dental Journal 168, 343-6.

22. Øksan T, Aktener BO, Sen BH, Tezel H (1993) The penetration of root canal sealers into dentinal tubules. A scanning electron microscopic study. International Endodontic Journal 26, 301-5.

23. Pashley DH (1992) Smear layer: Overview of structure and function. Proceedings of the Finnish Dental Society 88 (suppl. 1), 215-24.

24. Pecora JD, Cussioli AL, Guerisoli DMZ, Marchesan MA, Sousaneto MD, Brugnera-junior A (2001) Evaluation of Er:YAG laser and EDTAC on dentin adhesion of six endodontic sealers. Brazilian Dental Journal 12, 27-30

25. Pick RM. Using lasers in clinical dental practice (1993) Journal of American Dental association 124, 37-47.

26. Rome W, Doran EJ, Walker WA (1985) The effectiveness of glyoxide and sodium hypochlorite in preventing smear layer formation. Journal of Endodontics 11, 281-8.

27. Sen BH, Wesselink PR, Türkün M (1995) The smear layer: A phenomenon in root canal therapy. International Endodontic Journal 28, 141-8.

28. Siqueira JF, Araujo MC, Garcia PF, Fraga RC, Saboia Dantas CJ (1997) Histological evaluation of the effectiveness of five instrumentation techniques for cleaning the apical third of root canal. Journal of Endodontic 23, 499-502.

29. Sjögren U, Sundqvist G (1987) Bacteriologic evaluation of ultrasonic root canal instrumentation. Oral Surgery, Oral Medicine and Oral Pathology 63, 366-70.

30. Stabholz A, Zeltser R, Sela M, Peretz B, Moshonov J, Ziskind D (2003) The use of laser in dentistry: Principles of operation and clinical applications. Compendium 24, 935-48.

31. Takahashi K, Machida T, Kimura Y, Matsumoto K (1996) The morphological study of root canal walls with Er:YAG laser. Journal of Japan Endodontic Association 17, 197-203. 
32. Takeda FH, Harashima T, Kimura Y, Matsumoto K (1999) A comparative study of the removal of smear layer by three endodontic irrigants and two type of laser. International Endodontic Journal 32, 32-9.

33. Takeda FH, Harashima T, Kimura Y, Matsumoto K (1998a) Comparative study about the removal of smear layer by three types of laser devices. Journal of Clinical Laser Medicine and Surgery 16, 117-22.

34. Takeda FH, Harashima T, Kimura Y, Matsumoto K (1998b) Efficacy of Er:YAG laser irradiation in removing debris and smear layer on root canal walls. Journal of Endodontics 24, 548-51.

35. Takeda FH, Harashima T, Kimura Y, Matsumoto K (1998c) Effect of Er:YAG laser treatment on root canal walls of human teeth: A SEM study. Endodontics and Dental Traumatology 14, 270-3.

36. Tanji EY, Matsumoto K, Eduardo CP (1997) Study of dentin surface conditioning with Er:YAG laser. Journal of Dental research 76, 987.

37. Schoop U, Moritz A, Kluger W et al (2002) The Er:YAG laser in endodontics: results of an in vitro study. Laser in Surgery and Medicine 30, 360-364.

38. Versümer J, Hülsmann M, Schäfers F (2002) A comparative study of root canal preparation using Profile
.04 and Lightspeed rotary Ni-Ti instruments. International Endodontic Journal 35, 37-46.

39. Wayman BE, Kopp WM, Pinero GJ, Lazzari EP (1979) Citric and lactic acids as root canal irrigants in vitro. Journal of Endodontics 5, 258-60.

40. West JD, Roane JB (1998) Cleaning and shaping the root canal system. In: Cohen S, Burns RC, ed. Pathways of the Pulp, 8th edn; pp. 203-57. St. Louis, MO, USA: Mosby.

41. Weichman JA, Johnson FM (1971) Laser use in endodontics. A preliminary investigation. Oral surgery 31, 416-20.

42. White RR, Goldman M, Peck SL (1984) The influence of the smeared layer upon dentinal tubule penetration by plastic filling materials. Journal of Endodontics 10, 558-62.

43. Wigdor H, Abt E, Ashrafi S, Walsh JT (1993) The effect of lasers on dental hard tissues. Journal of American dental association $124,65-70$.

44. Wigdor HA, Walsh JT, Featherstone JDB, Visuri SR, Fried D, Waldvogel JL (1995) Lasers in dentistry. Laser in surgery and Medicine 16, 103-33.

45. Yamada RS, Armas A, Goldman M, Lin PS (1983) A scanning electron microscopic comparison of a high volume final flush with several irrigating solutions: Part 3. Journal of Endodontics 9, 137-42. 